\title{
Research as Design: Developing Creative Confidence in Doctoral Students Through Design Thinking
}

\author{
Nicola Ulibarri and \\ Amanda E. Cravens \\ Stanford University, \\ Stanford, CA, USA
}

ulibarri@stanford.edu; acravens@stanford.edu

\author{
Adam Royalty \\ Stanford University, \\ Stanford, CA, USA
}

adam@dschool.stanford.edu

\author{
Marilyn Cornelius \\ d.cipher pathways LLC, \\ Palo Alto, CA, USA
}

mc@dcipherpathways.com

\begin{abstract}
Anja Svetina Nabergoj
University of Ljubljana, Ljubljana, Slovenia
\end{abstract}

anja.svetina@gmail.com

\begin{abstract}
Material published as part of this publication, either on-line or in print, is copyrighted by the Informing Science Institute. Permission to make digital or paper copy of part or all of these works for personal or classroom use is granted without fee provided that the copies are not made or distributed for profit or commercial advantage AND that copies 1) bear this notice in full and 2) give the full citation on the first page. It is permissible to abstract these works so long as credit is given. To copy in all other cases or to republish or to post on a server or to redistribute to lists requires specific permission and payment of a fee. Contact Publisher@InformingScience.org to request redistribution permission.
\end{abstract}

This paper explores the benefits of design thinking training to enhance doctoral student problemsolving ability, creative confidence, and emotional well-being. Our team adapted the design thinking curriculum taught by Stanford University's Hasso Plattner Institute of Design to the challenges of developing and carrying out original research, and has taught thirteen workshops to over 240 graduate students, research staff, and faculty over two years. Using a design-based research framework, we reflect on our observation of the workshops, student debriefs, and a prepost survey of participants to assess the value of design thinking for doctoral education. We find that participants felt the workshops enhanced creativity, productivity, and confidence, participants appreciated applying the mindsets of a bias toward action and embracing experimentation to their research, participants learned to be mindful of their research process, and participants valued the emotionally supportive, nonjudgmental atmosphere cultivated in the workshops. The research suggests (1) that creative problem solving methods can be adopted by doctoral students and (2) that there is a demand for graduate training to more explicitly treat students' intellectual needs in tandem with their emotional needs to create happy, productive researchers.

Keywords: doctoral education, doctoral research, creative confidence, design thinking, emotional well-being, creativity in research 


\section{Introduction}

This paper explores the benefits of design thinking training to enhance doctoral student problemsolving ability, creative confidence, and emotional well-being. While the primary goal of doctoral education is to train students to conduct innovative, creative research and scholarship (Bargar \& Duncan, 1982; Halse \& Mowbray, 2011; Jones, 2013; Lovitts, 2008), creativity is rarely taught explicitly (Bargar \& Duncan, 1982; Lovitts, 2005). Moreover, learning to conduct original research is often lonely, frustrating, and difficult (Gardner, 2008; Kearns, Gardiner, \& Marshall, 2008; Lovitts, 2005, 2008).

The research team's experience as teachers and graduate students echoed this reality. We observed students grappling with the complexities of carrying out original research. Some students struggled with developing innovative yet testable research questions; others had trouble with logistical necessities like managing their time. Students felt that the available classes and texts on research design did not address these challenges, leading the students to feel stuck. This situation prompted us to create a curriculum to provide doctoral students with tools to address the varied challenges that arise while carrying out research and earning a doctoral degree.

We developed a curriculum applying design thinking, a flexible and repeatable process for conceptualizing and solving applied problems (Lindberg, Noweski, \& Meinel, 2010; Plattner, Meinel, \& Leifer, 2011; Rauth, Köppen, Jobst, \& Meinel, 2010), to address the problems faced by research students. We taught thirteen workshops for Stanford University graduate students, postdoctoral scholars, research staff, and faculty between March 2010 and September 2013. In this paper, we reflect on our observation of the workshops, student debriefs, and a pre-post survey of participants to build theoretical and practical understanding of how design thinking can be applied to doctoral education. This project is grounded in design-based research, a learning sciences approach in which the researcher creates an educational intervention and concurrently teaches and assesses the intervention in a "design experiment" (Anderson \& Shattuck, 2012; Brown, 1992). After developing curriculum for an intervention, the researcher/educator gathers real-time, mixedmethods data of their students during the curriculum and after it is taught. These observational and reflective data serve to inform future iterations of the curriculum and build theoretical and practical understanding of what worked and what did not.

In teaching the Research as Design workshops, we set out to provide a practical set of tools to help students move beyond feeling stuck and increase their creative confidence in conducting original research. However, we discovered that the workshops addressed other needs of graduate students, most notably emotional support and a team of peers who could non-judgmentally empathize with their experience (Jairam \& Kahl, 2012). This paper explores the multifaceted changes workshop participants report in their approach to research and life, including the adoption of mindsets that allowed students to be more comfortable with uncertainty, vulnerability, and failure; increased feelings of creativity and productivity; and the appreciation of a supportive atmosphere.

The paper begins with review of the literatures on creativity in scholarly research, the doctoral student transition from student to researcher, and design thinking as a tool to develop creative confidence. We then introduce an overview of our research approach, the workshop intervention, data and analysis methods, followed by a discussion of our findings. We conclude with implications for research and practice. 
Ulibarri, Cravens, Cornelius, Royalty, \& Nabergoj

\section{The Value of Creativity in Scientific and Scholarly Research}

Scholarly research happens in a messy, nonlinear process. An example of ill-defined problemsolving (Voss \& Post, 1988), research requires the scholar to define a problem that is only partially known in advance, and the scholar does not know whether an answer exists to the chosen problem until that answer is found. In increasingly specialized subfields of scholarship, a researcher may literally be the world's expert on her topic, with no one else to turn to when she encounters a dead end. Thus, research is not a well-structured problem-solving task, but a creative problemfinding and problem-crafting task (Schön, 1983).

In recent years, the complex, creative aspects of research have been amplified as many simpler problems have been solved. Gibbons et al. (1994) describe the extent of the resulting changes in science: "not only is the average number of authors per paper increasing, but much more significantly, so are the diversity of specialties and disciplines involved in the writing of a single paper and the range of institutions and organizations from which the authors originate. In addition, the geographical distribution of these institutions continues to broaden" (p. 34). The increasing interest in and focus on applied research adds additional complexity. As projects aim to influence policy or solve real-world problems, tensions arise between the demands of building theory and influencing practice.

Given the complex, ill-defined nature of conducting research, creativity is considered to be tightly linked to the innovation and impact of research (Anders, Elvidge, \& Walsh, 2009; Cravens, Ulibarri, Cornelius, Royalty, \& Nabergoj, 2014). Creativity is the production of unpredictable novelty and practical ideas based on it (Amabile, 1996; Runco \& Albert, 2010; Sternberg \& Lubart, 1999); in science, creativity focuses is on the originality and usefulness of knowledge (Heinze, Shapira, Rogers, \& Senker, 2009; Hollingsworth, 2012; Simonton, 2004). Behavioral traits of creative individuals include high levels of curiosity, motivation, tolerance for risk and ambiguity, and willingness to overcome failure (Sternberg, O'Hara, \& Lubart, 1997; Weinert, 2000), characteristics that make them highly self-efficacious (Bandura, 1994). .

\section{Graduate School and the Transition from Student to Researcher}

While creativity is a valuable asset for productive, innovative researchers, learning how to become an innovative researcher is challenging. As Lovitts (2005) observed, creativity is rarely taught: "Despite the apparent importance of creativity in graduate education, it is typically assumed that creativity is idiosyncratic and that advisers can do little to help their students develop into creative scholars" (p. 141). This means many students have to discern creativity's value by themselves and cultivate it in their research with little explicit guidance.

While earning a doctorate degree, students gradually transition from taking courses with a professor grading their performance to producing an original dissertation project and launching their careers as independent scholars (Grover, 2007). This transition is often a challenging one (Gardner, 2008; Lovitts, 2005, 2008; Spaulding \& Rockinson-Szapkiw, 2012). As compared to successfully completing problem sets, term papers, or course exams, conducting original scholarship is a messy, inconclusive process that requires not only more sophisticated analytic thinking, but creativity, tolerance for ambiguity and not knowing the right answer, and conscious management of one's own research process (Lovitts, 2008). Moreover, doctoral students face increasing pressures to publish and produce at a high rate (Jones, 2013).

These difficulties can lead to relatively high attrition rates from doctoral programs (Bourke, Holbrook, Lovat, \& Farley, 2004). The combination of feeling isolated (Ali \& Kohun, 2006, 
2007) and pressure to produce rigorous, innovative work creates a difficult social dynamicstudents are lonely but too busy or stressed to form meaningful friendships or a supportive social structure. At the extreme, the emotional and mental pressures of earning a doctoral degree can lead to depression, suicide, and even murder (Hall, 1998; Lovitts, 2005). On a lighter note, the sheer number of blogs and comic strips discussing or satirizing the $\mathrm{PhD}$ experience (such as http://xkcd.com/, http://phdcomics.com/, and http://whatshouldwecallgradschool.tumblr.com/ ) highlight the confusion, loneliness, and emotional toil encountered by emerging researchers. Meanwhile, there is relatively sparse research on the emotional well-being of graduate students (Hyun, Quinn, Madon, \& Lustig, 2006).

Despite the emotional and intellectual challenges of graduate school, some students make the transition to researcher relatively easily. Students with a fixed view of intelligence, who view graduate school as a series of tasks that require performance and proving their abilities, might have been successful in the coursework phase of a graduate degree. However, it is those displaying what Dweck and colleagues (Blackwell, Trzesniewski, \& Dweck, 2007; Dweck, 2006) term a growth mindset and Watkins (2010) terms a learning orientation — students viewing graduate school as a process of continually making mistakes that increase one's ability to perform better in the future-who are most likely to successfully make the transition to become independent scholars. In focus groups with high-producing PhD advisors, Lovitts (2008) found that displaying certain characteristics of six factors - intelligence, knowledge, thinking styles, personality, motivation, and environment - enabled students to successfully bridge the challenging transition and become innovative researchers. Some of these characteristics, such as analytical intelligence, use of formal knowledge, and motivation, are useful in both the purely student phase and in conducting research. However, students who make the transition with ease are not just good analytical thinkers, but show creative and practical intelligence, use informal and tacit knowledge in addition to formal knowledge, and are better able to deal with failure (Lovitts, 2008).

\section{Developing Creative Confidence}

Many of the characteristics of successful PhD students (Lovitts, 2005, 2008) and the behavioral traits of creative researchers (Cravens et al., 2014) overlap. From a process standpoint, successful $\mathrm{PhD}$ candidates and innovative researchers seek early feedback on their ideas, generate numerous potential research questions, and have concrete methods to identify which questions to pursue. Their mental outlooks allow them to tolerate and even embrace uncertainty, view failure as a learning opportunity, and be confident that a seemingly-disorderly process will yield results. These characteristics reflect a quality called creative confidence: "Having the freedom and courage to fail/take creative risks and the knowledge that all of the ideas you create have value" (Grossman-Kahn, 2011; see also Kelley \& Kelley, 2013). Creative confidence ties strongly to self-efficacy, "people's beliefs about their capabilities to produce designated levels of performance that exercise influence over events that affect their lives" (Bandura, 1994). If individuals know that they have the tools to creatively solve problems and view failure as a source of new skills while maintaining their efficacious attitude, logic follows that they are more likely to both succeed in solving problems and in producing more innovative ideas. Therefore, if we could instill creative confidence in graduate students, they would be more likely to succeed as doctoral students and as creative researchers throughout their career.

Design thinking is a set of mindsets and techniques for solving ill-defined, real-life problems (Rauth et al., 2010) while nurturing and encouraging creative confidence (Kelley \& Kelley, 2013; Lindberg et al., 2010; Seelig, 2012). Design thinking fits naturally into design domains like architecture and product design, but can provide value to any process requiring creativity and innovation as it delivers a flexible, repeatable methodology for generating ideas and finding solutions. As such, design thinking has historically been taught in design schools, but has been increasingly 
adapted for non-designers (Johansson \& Woodilla, 2008). Institutes like the Hasso Plattner Institute of Design (d.school) at Stanford University teach design thinking for a wide range of realworld problems (Dunne \& Martin, 2006; Plattner et al., 2011). The framework has been applied in management education (Zupan, Svetina Nabergoj, Stritar, \& Drnovšek, 2013), information and communications technology (Lindberg, Meinel, \& Wagner, 2011), medicine (McDonagh \& Thomas, 2010), social entrepreneurship (Cohen, 2012), and K-12 education (Carroll et al., 2010).

Despite this spread, there has, to date, been limited application of design thinking in the context of scientific or scholarly research. The basic process of innovative thinking is the same in science, the arts or business (Beveridge, 1980; Sawyer, 2006; Schön, 1983) since the way to a solution is not known beforehand and is thus impossible to predict logically. David Kelley, co-founder of the Hasso Plattner Institute of Design and the global design firm IDEO, says that design thinkers "have a methodology that enables us to come up with a solution that nobody has before" (Tischler, 2009, p. 1) - exactly the need of researchers producing original scholarship. This framework formed the pedagogical foundation of our curriculum intervention for doctoral students.

\section{Methodology}

\section{Design-Based Research Approach}

This paper leverages a design-based research (DBR) approach, which uses the iterative design and implementation of educational materials as the basis for research. DBR has an explanatory and advisory aim as it provides theoretical insights into how a particular teaching and learning approach can be promoted (Bakker \& Van Eerde, in press). As a curriculum is developed, researchers identify variables behind the curriculum's impact on students, relating those variables to existing theories and seeking to understand how the curriculum can evolve into a more powerful learning experience. Importantly, a DBR researcher holds that the key variables are continually being explored, never fixed, and that they depend heavily on the context of that specific curricular intervention (Collins, Joseph, \& Bielaczyc, 2004). In contrast to a randomized control trial, DBR's causal evidence is drawn from within the case, not from comparison to a control group. DBR allows the researcher to understand why a particular intervention worked as it did, gathering data and refining curriculum in real time, with all of the complexities of a real classroom and teacher (Bakker \& Van Eerde, in press). However, the findings from DBR may be limited to that particular setting, and are thus primarily useful for exploratory work, as was the case in this project, which sought to explore if design thinking could be a useful tool for doctoral students.

Wang and Hannafin (2005) argue that DBR should be iterative, pragmatic, grounded, integrative, and contextual. Our Research as Design workshops thus use an emergent curriculum that is continually iterated based on observations and learning from previous versions. The workshops are pragmatic and grounded because our pedagogy draws on existing design thinking work to create new student practices. The work is highly contextualized, as participants' individual experiences as researchers are the basis for many of the exercises. Finally, Research as Design is integrative because it relies on mixed methodologies including observations, surveys, student materials, and debriefs. These various data, collected throughout the curriculum design and implementation, form our understanding of the curriculum's impact and help us suggest design frameworks and theories (Edelson, 2002) for others to use.

\section{Workshop Intervention}

Our workshop is modified from the basic design-thinking curriculum taught by the Hasso Plattner Institute of Design at Stanford University (Stanford, CA, USA), with emphasis on the techniques 
our team has found to be most useful for researchers. Following experiential learning theory (Kolb, 1984; Kolb, Boyatzis, \& Mainemelis, 2000), we use an action-based, experiential workshop. Lecturing is kept to a minimum, and students learn via activities and exploration paired with coaching from the teaching team. The minimization of lecturing is also intended to force participants out of their normally analytical, deliberate mode of being and into an experimental, creative, and playful approach. This shift allows participants to see challenges they are facing in a new light and be freer in developing potential solutions.

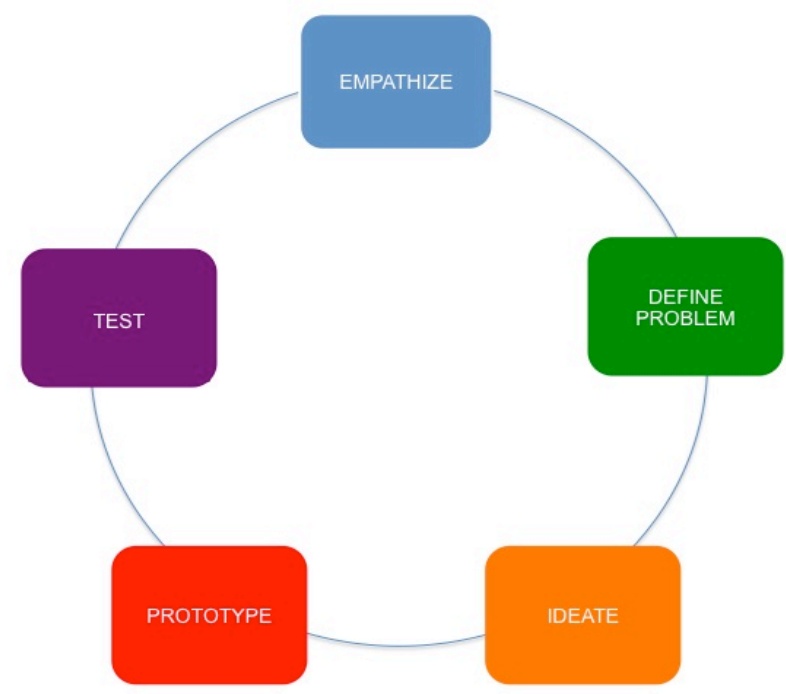

Figure 1: The Design Thinking Innovation Process

Adapted from Hasso Plattner Institute of Design at Stanford (2010)

The basic practice of design thinking is the design thinking innovation process, which is often represented by five distinct stages (Figure 1). Following this cycle, our workshops start with empathize, where we introduce techniques for students to investigate the nature of a problem and the underlying emotions or needs influencing it through interviewing or self-observation. Second, in define, we help them identify the core of the problem - which may not be immediately obviousand then reframe the problem so that it is a concrete, tractable statement. Third, in ideate, students brainstorm possible solutions to the problem that they have identified. Finally, in prototype and test, the students create a physical representation of their selected idea and test a rough version of a solution for one or more of their ideas.

Throughout the workshop, students work in multi-disciplinary teams. Teamwork provides multiple perspectives on a problem and adds a sense of detachment, which is particularly important when dealing with something as dear-to-heart as one's dissertation research. We also invite former participants to coach, providing both extra teaching staff to assist new participants and a repeated experience for students who want additional exposure to the mindsets and techniques.

We have developed the curriculum iteratively, incorporating the teaching team's observations and student feedback gathered during structured debriefs. For instance, we observed that students were finding value in the techniques we taught, but that they didn't feel they had the confidence to use them without intensive coaching. Further, they had trouble detaching themselves enough from their own personal research challenges to problem-solve effectively. To address these needs, we created a four-day, extended version of the curriculum to replace the previous day-long versions. In this extended version, students practice the design-thinking cycle four times and have time between each session to apply techniques and test solutions in the real context where they 
will be used. To warm students up to the creativity and open-mindedness needed for design, we begin with a pre-framed challenge, such as, "How might a busy researcher make time for fruitful, spontaneous interactions?" Then, once they have a little experience with a design cycle and have started to embody some of the playfulness needed for creativity, we repeat the design process with successively individualized prompts, consciously scaffolding for their level of expertise (Ambrose, Bridges, DiPietro, Lovett, \& Norman, 2010). After the predefined, anonymous prompt, students work in teams around a shared, jointly-identified problem, and then solve individually-defined problems (but with extensive coaching and interpersonal feedback).

\section{Participants}

We taught thirteen workshops between 2011 and 2013, including two iterations of the four-day workshop in May and September 2013. In this paper, we treat the extended versions as our primary source of information and note whenever data are from earlier workshops.

Potential participants were invited by emails announcing the workshop sent to a mix of departmental and interdepartmental mailing lists on campus. A number of participants were also invited through word-of-mouth, as we encouraged former participants to invite colleagues they thought would benefit from the workshop. Prospective students completed an application detailing why they wanted to participate and what challenges they were currently facing in their research; participants were then admitted to the workshop on a first-come, first-served basis. The workshops attract a diverse student body and are in consistently high demand. The courses generally fill quickly (within a week of opening registration), and we always have a wait-list.

In all thirteen workshops, we have had approximately 240 participants, spread between early-, middle-, and late-stage doctoral students, as well as a few masters students, postdoctoral scholars, faculty members, and research and administrative staff. In this paper, we focus only on the graduate student experience, as other groups lack sufficient numbers to generalize about their experience.

Participants came from a broad array of disciplinary and interdisciplinary backgrounds, representing every school on the Stanford campus (Table 1). Approximately one-quarter of participants had some previous experience with design thinking.

While our participants are fairly representative of the disciplinary background and level of expe-

\begin{tabular}{|c|c|c|}
\hline \multicolumn{3}{|c|}{ Table 1} \\
\hline \multicolumn{3}{|c|}{ WORKSHOP PARTICIPANTS BY DISCIPLINE } \\
\hline School & Workshop Participants & $\begin{array}{c}\text { Stanford Graduate } \\
\text { Enrollment, 2013-2014 }\end{array}$ \\
\hline Humanities and Sciences & $88(37 \%)$ & $2261(25 \%)$ \\
\hline Engineering & $59(25 \%)$ & $3381(38 \%)$ \\
\hline Earth Sciences & $35(15 \%)$ & $355(4 \%)$ \\
\hline Law & $9(4 \%)$ & $631(7 \%)$ \\
\hline Medicine & $29(12 \%)$ & $949(11 \%)$ \\
\hline Education & $16(7 \%)$ & $355(4 \%)$ \\
\hline Business & $4(2 \%)$ & $971(11 \%)$ \\
\hline
\end{tabular}


rience of the Stanford graduate student body as a whole, they are importantly self-selected. Students who opt to participate in an extracurricular learning activity like the workshop may be motivated differently than their peers in ways that affect our results. First, our participants may have faced more extreme challenges in their research, thus prompting the desire to participate in the workshop; this would indicate that our observations about the need for emotional support might be more extreme in participants relative to their peers. Second, those who chose to participate may have more desire for self-improvement or greater openness to new approaches, and therefore would be more willing to actually adopt new mindsets and practices relative to their nonparticipating peers.

\section{Data Collection and Analysis}

Data informing this reflection stem from several sources (Figure 2).

ETHNOGRAPHIC MATERIAL
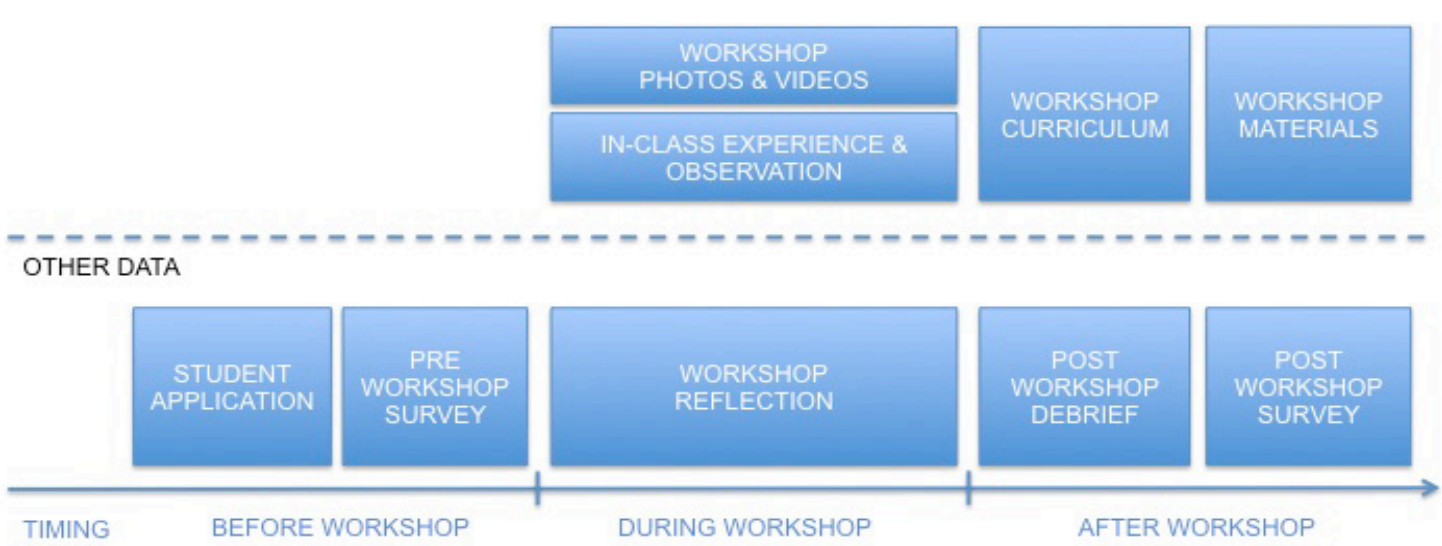

Figure 2: Data Sources and Collection Process

As called for by the DBR paradigm, our lived experience as educators/researchers is the main data informing this study. We captured these ethnographic data in a variety of formats. At each workshop, we photographed and video recorded participants and their solutions, and collected workshop materials (copies of worksheets, brainstorms, and other drawn and written work) to see how students applied our coaching to their individual problems. We also wrote real-time observations of particularly interesting outcomes, ideas for future workshops, or places where students appeared to be struggling. All of this ethnographic material informs our findings as a reminder of the lived experience.

Other data sources include student applications to the workshop; an incoming participant survey capturing student approaches to problem-solving, reflection, feedback, and creativity; student debriefs conducted at the close of each workshop; and a follow-up survey of participants conducted after the workshop.

In their applications to the workshop, students were asked why they wanted to participate, what background they had with research and design thinking, and what challenges they were currently facing in their research.

Participants completed an anonymous pre-survey at the start of the first session, with questions exploring how they approach problems faced in their research, how frequently they reflect on their research process, and on their relationship with their advisor. 
Student debriefs serve as a particularly important source of immediate reactions to and reflections on the workshop. At the close of each workshop, we conducted a debrief session. We asked students to reflect on what similarities and differences they observed between the ways they usually approach problems in their research and their experience during the workshop. We then used a debrief format common to design thinking, called "I like, I wish, what if." It asks students to share components of the workshop that they liked or that worked well; to reflect on things that they wished had been available or were done differently; and to envision possibilities using "what if..." statements. Debriefs were transcribed by one of the team members. Debriefs were transcribed anonymously unless a statement was made by a member of the teaching team, so we cannot trace statements to any particular types of students (such as academic discipline or stage of training).

A follow-up survey was administered roughly two months after each extended workshop. The survey was conducted online using Qualtrics; all responses are anonymous. The follow-up survey began with the research process questions from the pre-survey. Other questions explored how frequently students used the various techniques taught in the workshop and why they used them, level of confidence using each technique, and overall reflections on the RAD workshop and its value, as well as some basic demographics relating to their field of study and level of education. Most survey questions were free response; several questions (as reported in the findings section) were multiple-choice or Likert scale. Follow-up surveys were sent to all 48 extended-workshop participants, and we received 27 complete responses for a response rate of $56.3 \%$.

For questions involving quantitative analysis, survey data were cleaned and then imported into SPSS statistics package version 21. Descriptive and comparative statistics were explored. Specific tests are shared in the findings section. The debrief transcriptions and open-response survey questions were coded using NVivo qualitative analysis software version 10. Following a grounded theory (Glaser \& Strauss, 1967) approach, debriefs were initially open-coded, and then codes were grouped into emergent categories to capture participant experiences. Some themes reflect particular mindsets and techniques derived from design thinking; others incorporate more freeform evaluations of the workshop experience.

We are working with self-reported data (the debriefs and surveys) as our primary source of information, in combination with our team's observations of the workshops. While reported data is subjective, we are interested in what participants valued about the workshop - their perspectives - not necessarily exact usage statistics. Likewise, we are not looking at changes in overall productivity or creativity as much as reported changes, with the understanding that what students feel — whether they considered themselves empowered by the workshop — is as at least as important as whether they actually became more productive on some objective measure. Moreover, confidence and self-efficacy (Bandura, 1994) are close predictors of actual behavior change, so we can safely assume that changes in reported confidence are associated with behavioral changes.

\section{Findings}

Table 2 summarizes major findings from the analysis of qualitative data. The subsections below describe these findings in greater detail. 
Table 2

\section{KEY OUTCOMES OF DESIGN THINKING TRAINING FOR DOCTORAL EDUCATION}

Participants feel the workshop led them to be more productive, creative, and confident in their research.

Students reported that design mindsets -which include radical collaboration, bias toward action, and embracing experimentation-were useful approaches that could help them move beyond feeling stuck.

Participants felt they came away with greater respect for mindfulness and reflection about their research process.

Students found the workshop atmosphere emotionally empowering and a safe space to be vulnerable, and contrasted it to the normal way things are done in their research lives.

\section{Participants Feel the Workshop Induces Creativity, Productivity, and Confidence}

Participants feel the workshop led them to be more productive, creative, and confident in their research, all key components of creative confidence (Kelley \& Kelley, 2013).

Regarding productivity, multiple participants noticed significant changes in their ability to solve problems they'd attempted to address previously. As several students reflected, "Today felt more productive (even though I normally think a lot about these same problems) - probably because I was forced to think in a more focused way" and "This makes me work more efficiently, I analyzed these problems before but very slow and limited ideas." One participant proclaimed: "if we approach[ed] research this way, [we] could be much more productive."

Students also felt that the workshop sparked their creative juices. One participant was presently surprised at the "amount of creativity": "I think I was curious and interested and walking in and there's no wall...blocks like legos... a little bit floofy... we play with stickers and pipe cleaners... [but] the amount of creativity we produced and I produced [was] much more powerful than I expected." Other participants found the workshop "freeing. I came up with new ideas I would not have usually come up with."

Some participants also reported increased confidence. A $1^{\text {st }}$-year natural scientist found that the most valuable takeaway was, "confidence in overcoming the problem [he] had at the time." A $2^{\text {nd }}-$ year scientist would recommend the workshop to colleagues by "tell[ing] them that the workshop can give a new perspective and set of tools for problem solving, making you more productive and feeling in control." Empowerment was especially strong for those participants who returned to coach for us - that they finally "got it" when they were able to step out of their own problem and teach the generalizable method to others.

We captured student's opinions on the workshop in a creative confidence scale, scored on a 7point Likert scale from Strongly Disagree to Strongly Agree (3 is neutral). Descriptive statistics for these questions are reported in Table 3. Students' answers ranged from neutral to strongly agree that the workshop improved their ability to give feedback and changed how they approach their work and research, and they unanimously agreed that the RAD workshop gave them confidence to address challenges and was fun. 


\section{Table 3}

\section{CREATIVE CONFIDENCE DESCRIPTIVE STATISTICS ( $\mathbf{N = 2 7 )}$}

\section{QUESTION}

MEDIAN

The RAD workshop made me feel more confident about facing challenges that arise in conducting research.

The RAD workshop was fun.

The RAD workshop changed the way I view my research

The RAD workshop gave me tools to use when I get stuck.

The RAD workshop changed the way I approach my work.

The RAD workshop improved my ability to give feedback on colleagues' research content.

The RAD workshop improved my ability to give feedback on colleagues' research process.
6

5.67

6

6.26

6

5.52

6

5.74

5

5

5.19

5

5.33

\section{Students Found the Design Mindsets Refreshing and Useful}

Through repetitively experiencing and applying the design thinking innovation process, students are exposed to a series of mindsets cultivated by design thinkers, which include radical collaboration, bias toward action, embrace experimentation, and mindfulness of process (for a full list, see Hasso Plattner Institute of Design at Stanford, 2010). In the workshop, students resonated with these mindsets and alluded specifically to them in debriefs and the survey. Importantly, the curriculum does not explicitly teach these mindsets; instead, through familiarity with the specific tools and the design process, paired with instructors actively modeling the mindsets, students gradually adopt the design-thinking mindsets. The mindsets describe a designer's mental attitude and orientation toward approaching problems (Hassi \& Laakso, 2011). As Rauth et al. (2010, p. 6) note, "mindsets can be seen as the establishment of a bias towards creative behavior in situations where students are facing situations in which they are uncertain or problems where there is no solution at hand."

Radical collaboration is the intentional creation of diverse teams to help solve problems. Working through research and personal problems with a team was new for many participants, particularly a multidisciplinary team that might know nothing about their disciplinary domain. Many participants found the experience refreshing: "I think I thought group work was super inefficient... but this work really killed that idea." They found that it added "enthusiasm... alone I hit a bump, and slow down, but [working] in a group with fast pace keeps me going." Other participants reported liking the "Diversity of [the] group, [and the] chance to see how other people think and work."

Overall, students appreciated the chance to work with a team during the workshop, finding it both different than their usual approach and useful. In the survey, multiple participants reported seeking to recreate that team dynamic after the workshop, particularly for feedback. An engineer wrote, "One of the things I do more often and which I find more helpful than most of the others is to pull aside a colleague and ask them to help me solve a problem, which often involves sketching or writing stuff on the whiteboard, and of course, conversation." Likewise, a social scientist said, "I tend 
to work solo and after the workshop am striving to be more collaborative in the design phase." Another social scientist really liked "the focus on using this process on myself and my team. I can see that people really benefit from interacting with others from differing perspectives when planning research; I know I did." It is important to note, however, that this sentiment was not universal; some participants wanted more practice working alone with the techniques since that's how most research plays out.

Bias toward action refers to an inclination toward "action-oriented behavior, rather than discussion based work" (Crandall, 2010). As research students, participants came to the workshop with the tendency to think about, not act on, problems. When asked about how they approached being stuck in the pre-survey, the majority wrote about thinking ("Take a step back and think about it"), reading ("Look for additional literature related to my research topic"), or just taking a break ("Work on something else"). In the workshop, students appreciated "being reminded of value of doing rather than spending weeks thinking." One $2^{\text {nd }}$-year natural scientist found the newfound bias toward action valuable for feeling like she was making progress:

"It's time to get out of your head. You know the saying 'see the ball, be the ball?' Well, this class is 'see the research, be the research!' The class will help you take those feelings of dread or panic and channel them into productive efforts to get you moving again."

For others, an action as simple as reaching out could make a big difference: "It's important to ask for feedback...others are busy... but better to ask instead of being stuck for weeks."

Embrace experimentation is the mindset of failing early and often to facilitate quick, iterative learning and feedback. In the pre-surveys, many students reported striving for perfection before sharing anything, for fear that their ideas (and by extension, they) would be rejected. As one participant reported, "We're not allowed to fail so often in research." However, after the workshop, students found it useful to seek feedback on their ideas earlier, before they had invested a lot of time and effort. For instance, a social science student wrote how his problem solving process had changed: "Basically [I] ask more people/ research center for feedback on my research, dare to present, etc... We just need to look for opportunities around us and accept to be confronted to new questions, suggestions and criticisms." As an engineer wrote, "I have also learned to send stuff faster to my advisor - as in here is the beta I know it sucks but please provide feedback anyway." Students appreciated the reminder "that uncertainty and ambiguity is ok; even if you don't get it, plough through," demonstrating a wonderfully experimental mindset. (As a quick caveat, according to our pre-post survey, there is not a statistically significant change in how early students report seeking feedback on various research-related challenges, perhaps suggesting the shift is less a behavior than an attitude shift, or that they are feeling more empowered and less anxious about feedback when they do seek it.)

For our participants, an important component of learning to embrace experimentation was learning to be detached from any particular outcome. Participants found this particularly challenging, because "research is your baby" and so they felt that the outcome really mattered for their reputation and career. However, they reported that learning to detach more was freeing. As one participant described, "I was less attached to the outcome [of the process] today. I came in interested in the process, so it let me start from the beginning and see how useful it is... [Using a] beginner's mindset... I can make it an opportunity instead of something awful."

In the workshop, one concrete way we helped students create detachment was to require the deliberate generation of multiple (3-5) options at every phase of the design process, which reduces attachment to any single question or solution (Dow et al., 2010). Participants particularly liked this technique. As an education student reported, "I ask people to help me brainstorm more and I am not as attached to the first ideas. I do not call them 'mine'; that way I can let go of them more easily." 


\section{Participants Learned to Be Mindful of Their Research Process}

The final mindset, mindfulness of process, we feel is important enough to merit its own section. Through the workshop, students learned to be reflective about their research and problem-solving process as well as those of others. For some, this was a novel concept: they liked "the process of seeing my research as thought process that could be improved and that the way I work can be changed," "the awareness that there's a way to [problem solve] systematically," and "that it's very structured, you set intermediate goals and deliverables instead of [the] target of publishing a paper." In the long term, a $3^{\text {rd }}$-year engineering student carried away "the idea that design thinking (especially in the early exploratory stages) actually allows the subsequent 'problem solving' steps to be more structured and focused. It is worth investing in the time and effort early to avoid wasting time later." Describing her approach to being stuck after the workshop, a natural scientist wrote, "I try to pinpoint exactly where in the process the problem lies, and then taking that as a starting point, I explore alternatives." A $5^{\text {th }}$-year engineer reported, "Knowing when to use synthesis vs. analysis [is a] great idea/skill!," a key component of knowing where in the process one is.

Part of mindfulness of process is learning the importance of taking time to reflect on what to do next, what's working or not working, etc. Participants found this difficult in the culture of academia: "I don't often take the time to think about problems - you keep moving to meet deadlines." One engineering participant wrote a thank you email emphasizing that he appreciated that reminder: "we as researchers too often just put our heads down and go go go without taking the time to reflect on the process, and the course you've put together really goes a long way to providing a useful set of... tools." Once again, there was not a statistically significant change in how frequently participants say they reflect on their research process in the pre-post survey, suggesting an attitude but not necessarily a behavioral shift.

\section{Participants Appreciate the Intellectual and Emotional Difference in Atmosphere from Their Day-To-Day Research Environment}

In debriefs and the survey, participants strongly appreciated the difference in atmosphere created by the workshop to that of their normal working environment. Participants report that graduate school can be isolating, that the feedback they receive is often critical and not always inspiring, and that getting stuck can induce a feeling of paralysis. As a $2^{\text {nd }}$-year humanities student wrote in the pre-survey, when stuck his approach was to "Get overwhelmed with panic... I feel overwhelmed by the entire task and not nearly focused enough."

In contrast, participants found the workshop to foster an emotionally supportive, nonjudgmental atmosphere. They liked the "safety of community" and that "everyone has had a no judgment attitude, positive space." At the workshop, "Everybody here feels safe to make mistakes; [the] facilitators made us feel so safe, I could fail and everybody was fine with that." An engineer valued being able to "understand that we are not alone with our problems and that we need to exchange with people around us about them." A $7^{\text {th }}$-year natural scientist appreciated, "The notion that people have done a lot of hard thinking about the squishy difficulties of solving real problems; this means that when I feel like I'm stuck on my particular problem, perhaps someone knows another approach for when I get stuck. [It gives me] Hope!" As a student who had come back to coach reported to us, "[O]ne of the benefits I saw people walking away with was a renewed sense of possibility and hope...grad school can narrow you down...to get out of feeling hopeless... It's like a quick group therapy." Participants particularly liked that the teaching team was vulnerable too-that we "embodied the spirit of the process" and shared our own experiences and challenges with research and with the design process. 
In a very explicit statement of the difference in atmosphere, at the workshop one student summarized, "[I] never really felt singled out...I have a supportive lab but I find when you're pitching ideas you're alone in front of people, instead of brainstorming with people."

\section{Not Everyone Liked the Workshop or Found It Useful}

While the majority of participants appreciated the workshop, the sentiment was not universal. There were a few participants who didn't accept our premise from the start and thought the workshop was too "fluffy" to have any academic merit. Beyond these systemic critiques, we received lots of constructive criticism about making our instructions clearer or ways to better scaffold student experiences. Every workshop had suggestions for improvement, and we still have a lot to learn from our current iteration.

In addition, while many people valued the workshop, some participants acknowledged that askedfor shift in ways of thinking and doing was scary. As one student shared, "the [5-Whys] exercise [asking why to find a root cause] was most difficult exercise I've done in weeks. You get stuck usually and don't think of what is the real problem...we usually try and hide...," revealing that participants had to seek a vulnerable place in order to discover what wasn't working in their process and move forward. (The need to get students to work into and past that vulnerable stage was one of the primary reasons we developed the multi-day version of the workshop, as a way of providing repeat exposure to build self-efficacy.)

\section{Discussion}

We set out to provide a curriculum that would introduce doctoral students to a repeatable process they could use to address the types of problems that arise while conducting research and completing a dissertation, thereby increasing their creative confidence. The consistency of responses in the creative confidence scale suggests that we were successful in this regard. However, the piece of the workshop that seemed the most powerful-where student responses were the most impassioned - was the emotional difference from students' day-to-day research lives, especially the attitude that whatever happens in your research, you're still a worthwhile person. In debriefs especially, students felt that the atmosphere of the workshop was beneficially different than their own or their labs' more critical approach to research challenges. Having a supportive environment gave them permission to explore without repercussions, while learning specific techniques to use in any situation made them feel more productive and creative. We explore both of these outcomes in the following sections: the "intellectual" impacts on problem solving, creativity, and productivity, and the "emotional" impacts of safety and non-judgment. We conclude that the two are inherently connected.

\section{Building Innovative, Productive Researchers}

Productivity and creativity are commonly seen as valuable traits for researchers; participants' responses suggest that the workshop improved both. Prior to the workshop, multiple students reported being paralyzed when faced by an unanticipated barrier or, at best, needing to switch tasks or take an extended break prior to revisiting the problem. The workshop provided students with tools to efficiently work through barriers, potentially leading to students' increased feeling of productivity relative to just ignoring the problem or simply thinking about it incessantly. Creativity was also improved, particularly in that students felt that they developed ideas and solutions they would not have normally found.

Here, it is important to note that we are discussing perceived changes in productivity - we have no data comparing students' work outputs to what they might have achieved absent the workshop. However, for a research student who is feeling overwhelmed by a problem or a task, the confi- 
dence of having a pre-defined way to focus their attention in solving that problem and thereby get to a place where they no longer feel stuck might be as important as whether they actually make more progress. By developing the confidence to learn from and harness failure and vulnerability, students become more efficacious problem solvers (Bandura, 1994).

\section{The Value of Treating Students as Whole Humans, Not Just Productive Researchers}

Beyond the traditionally valued creativity and productivity, participants were deeply moved by the supportive environment of the workshop and often emphasized the difference from their normal experience in graduate school. In particular, students appreciated the chance to work with a team in a supportive, non-judgmental atmosphere. While critique is an important part of academic work - it is the striving for perfection and always seeking more that drives quality research - the fact that students so strongly appreciated supportive critique suggests that perhaps a different balance between constructive criticism and non-judgment is needed, particularly in the early stages of idea development. If students are anxious that any little flaw might invoke a degree of critique they are not yet prepared to encounter, rather than viewing flaws as a learning opportunity, they are more likely to be focused only on getting it "right" and protecting themselves from feeling vulnerable rather than on exploring the new options and approaches necessary for innovative work.

Students reported that the judgment and critique they fear came from both external sources (advisors, lab groups, peers) and from within themselves. This suggests that the change is needed at both an individual and organizational level: individuals have to give themselves permission to fail, just their advisors need to give them permission to fail.

It has been noted that the mental health needs of graduate students are high and that insufficient attention has been paid to their mental happiness (Hyun et al., 2006). However, this view focuses on the negative - that poor mental health can detract from student performance. We suggest that the converse is also true: cultivation of emotional intelligence can actually increase productivity and creativity. A study of successful scholars at a top research university found that one trait shared by those doing innovative scholarship was being able to regulate their own emotions, particularly regarding uncertainty, ambiguity and unpredicted obstacles (Cravens et al., 2014). Moreover, social support has been shown to be critical for doctoral student success (Jairam \& Kahl, 2012), particularly for women (Haynes \& Bulosan, 2012). These findings, paired with our participants' reaction to how refreshing it was to work with a team and to being vulnerable in a creative, supported manner, suggest that cultivating emotional resilience might ultimately increase the quality of scholarship produced. Universities might therefore benefit from exploring the value of fostering a positive social atmosphere that allows for supportive critique and develops students' inter- and intrapersonal emotional intelligence (Goleman, 2005; Mayer \& Salovey, 1993).

\section{The Need to Reflect and Customize}

While the design thinking curriculum is generally taught as a series of steps that innovators can use to solve problems, those specific steps are simply building blocks toward larger mindsets that design thinkers consider invaluable for creative confidence. Therefore, for an experienced designer, less attention is paid to following the cycle in a linear fashion than to reflecting where in the process one needs to move next, complemented by a constant bias toward action and experimentation. In other words, different aspects of the design process will be used to different degrees, based on the problem at hand and individual temperament. Our experience suggests that this individualized approach is especially important for researchers, given the huge variety of ways research is conducted by discipline and the very different types of problems faced by re- 
searchers depending on stage in the research process. While all of the techniques and mindsets were valued by a subset of participants, very few students reported applying the innovation cycle in whole when they were faced with a problem. More frequently, students took our overall approach and turned it into a "choose-your-own-adventure" exercise. Participants applied the particular techniques that resonated most with their personalities and the problems they faced. We view this as success because it implies that students had the freedom to choose what they wanted and the reflective attention to know what would work best for them.

This reality makes mindfulness of process even more important. If a student is aware of his or her current stage in the research process, it can help provide direction for problem solving in a given moment. Essentially, mindfulness of process encourages students to become ever more expert reflective practitioners (Schön, 1983, 1990). For reflection to work, the student needs to take some time to notice where in the process he or she is. If students rush through life without pausing to notice and reflect on what the problem is, what they know about it, and what they might do about it, they miss many opportunities to redirect their efforts in potentially more productive or beneficial ways.

Creating time for reflection also gives the mind time to sift through options in the subconscious, without immediately picking the first idea that comes to mind. Learning to refrain from immediate critique sometimes is necessary to move beyond one's initial assumptions or automatic conclusions. Sometimes a seemingly bad or wacky idea can become a valuable gem with a little reframing, but if you self-censor, you miss that opportunity. As one student wrote, the workshop taught the value of the "idle yet focused mind"- that by relaxing a little bit one could enhance creativity. This echoes Loehle's (1990) essay on increasing creativity in research, in which he encourages students to take the time to be bored and inactive, and to daydream.

\section{Implications for Research and Practice}

This study has begun an investigation into mechanisms to build creative confidence among doctoral students in their research process. Although our study provides promising results and points to important initial future directions, we believe much more research in this area is necessary. Our workshop has been provided to a small proportion of the graduate students at Stanford University. The students who attend the workshops are self-selecting, so they might be more amenable to the sorts of mental and emotional changes we encourage than the average student. While our participants envisioned numerous ways to expand the curriculum across the campus-i.e., to lab groups or as a required section in new student orientation - additional research would be necessary to know whether expanding this specific workshop would hold value, or whether it is only the subset of students who are motivated to explore new ways to improve their research process who benefit. However, based on our team's experience, offering a design curriculum in the early years of the $\mathrm{PhD}$ would be optimal, before students have become entrenched in a particular way of doing research and a particular project. Repeat exposure and/or encouraging more senior students to act as coaches also seems potentially beneficial, as students get more and more fluent in the process and confident with techniques through repeat attendance and coaching.

This research suggests additional implications beyond simply replicating our curriculum. The current prevailing approach, of treating graduate students' intellectual needs separately from their emotional needs, does not appear to be creating happy, productive researchers. While the value of viewing students as whole people is understood for undergraduate students (Ambrose et al., 2010), our experience suggests this perspective needs to be extended to doctoral students. Some campuses have begun providing opportunities for training in emotional intelligence, mindfulness practice, and other tools to manage emotional needs. However, explicitly incorporating this approach into curricula for graduate students and training for mentors - rather than keeping it as a separate, extracurricular opportunity for individuals to seek out — would allow emotional and in- 
tellectual abilities to develop in tandem and (our experience suggests) create more creative and productive researchers. Of course, additional research is needed to verify whether this explicit coupling of social and emotional development is useful. Anecdotal evidence from business leaders' productivity and innovation (Goleman, 2004; "Mindfulness in the corporate world," 2012) supports the hypothesis that it would be.

Another potential approach stemming from this research is cross-disciplinary support systems for graduate students. While lab group meetings and department brown-bags provide the opportunity for feedback and (to some extent) emotional support, students appreciated receiving feedback from peers outside their discipline. The creation of cross-campus, multi-disciplinary working groups might allow for this type of feedback.

This study suggests the importance of creative confidence for doctoral education. Through design thinking training and similar approaches that integrate emotional and intellectual needs, students can be empowered to take control of their own research process and potentially avoid the emotional difficulties doctoral students often experience. By teaching a repeatable, explicit approach to problem solving, the workshops helped students feel more control over their research process and approach inevitable difficulties as learning experiences rather than evidence of failure. These results suggest the power of such an approach to aid advisors, administrators, and students themselves in improving the doctoral student experience.

\section{Acknowledgments}

The Research as Design workshops were made possible by a SPICE (Student Projects for Intellectual Community Enhancement) Grant from the Vice Provost for Graduate Education, the Emmett Interdisciplinary Program in Environment and Resources, and the Hasso Plattner Institute of Design at Stanford University. Special thanks go to Banny Banerjee and Nicole Ardoin for helping us develop and reframe the workshop curriculum, to Kathryn Segovia and Jeremy Utely for helping us iterate on the design thinking tools and to Chris Golde for her input on the importance of creativity in doctoral education. We would also like to thank Deborah Wojcik and Thomas Ehrlich for comments on early versions of this manuscript.

\section{References}

Ali, A., \& Kohun, F. (2006). Dealing with isolation feelings in IS doctoral programs. International Journal of Doctoral Studies, 1, 21-33. Retrieved from http://www.ijds.org/Volume1/IJDSv1p021033Ali13.pdf

Ali, A., \& Kohun, F. (2007). Dealing with social isolation to minimize doctoral attrition - A four stage framework. International Journal of Doctoral Studies, 2, 33-49. Retrieved from http://www.ijds.org/Volume2/IJDSv2p033-049Ali28.pdf

Amabile, T. M. (1996). Creativity and innovation in organizations. Harvard Business School, 5, 396-239.

Ambrose, S. A., Bridges, M. W., DiPietro, M., Lovett, M. C., \& Norman, M. K. (2010). How learning works: Seven research-based principles for smart teaching. San Francisco, CA: Jossey-Bass.

Anders, K., Elvidge, L., \& Walsh, E. (2009). Doing creative research: A good practice guide for postgraduate researchers in STEM disciplines. Graduate School, Imperial College London. Retrieved from https://workspace.imperial.ac.uk/graduateschool/Public/Creative $\% 20$ Research/PG\%20in\%20STEM.pd $\underline{\mathrm{f}}$

Anderson, T., \& Shattuck, J. (2012). Design-based research a decade of progress in education research? Educational Researcher, 41(1), 16-25. 
Bakker, A., \& Van Eerde, D. (in press). An introduction to design-based research with an example from statistics education. In A. Bikner-Ahsbahs, C. Knipping, \& N. Presmeg (Eds.), Doing qualitative research: methodology and methods in mathematics education.

Bandura, A. (1994). Self-efficacy. In V. S. Ramachaudran (Ed.), Encyclopedia of human behavior (Vol. 4, pp. 71-81). New York: Academic Press.

Bargar, R. R., \& Duncan, J. K. (1982). Cultivating creative endeavor in doctoral research. The Journal of Higher Education, 53(1), 1-31.

Beveridge, W. I. B. (1980). Seeds of discovery: A sequel to the art of scientific investigation. New York: Norton.

Blackwell, L. S., Trzesniewski, K. H., \& Dweck, C. S. (2007). Implicit theories of intelligence predict achievement across an adolescent transition: A longitudinal study and an intervention. Child Development, 78(1), 246-263.

Bourke, S., Holbrook, A., Lovat, T., \& Farley, P. (2004). Attrition, completion and completion times of PhD candidates. Presented at the AARE International Education Research Conference 2004, Melbourne. Retrieved from http://nova.newcastle.edu.au/vital/access/manager/Repository/uon:2422

Brown, A. L. (1992). Design experiments: theoretical and methodological challenges in creating complex interventions in classroom settings. Journal of the Learning Sciences, 2(2), 141-178.

Carroll, M., Goldman, S., Britos, L., Koh, J., Royalty, A., \& Hornstein, M. (2010). Destination, imagination and the fires within: Design thinking in a middle school classroom. International Journal of Art \& Design Education, 29(1), 37-53.

Cohen, J. (2012, March 19). Harnessing mobile tech and students to promote development in Kenya. Retrieved January 31, 2014, from http://www.gsb.stanford.edu/news/headlines/cohen-mobile-kenya.html

Collins, A., Joseph, D., \& Bielaczyc, K. (2004). Design research: Theoretical and methodological issues. Journal of the Learning Sciences, 13(1), 15-42. doi:10.1207/s15327809j1s1301_2

Crandall, R. (2010, August 26). Bias toward action. The k12 Lab Wiki. Retrieved January 31, 2014, from https://dschool.stanford.edu/groups/k12/wiki/548fb/Bias_Toward_Action.html

Cravens, A. E., Ulibarri, N., Cornelius, M., Royalty, A., \& Nabergoj, A. (2014). Reflecting, iterating, and tolerating ambiguity: Highlighting the creative process of scientific and scholarly research for doctoral education. International Journal of Doctoral Studies, 9, 229-247. Retrieved from http://ijds.org/Volume9/IJDSv9p229-247Cravens0637.pdf

Dow, S. P., Glassco, A., Kass, J., Schwarz, M., Schwartz, D. L., \& Klemmer, S. R. (2010). Parallel prototyping leads to better design results, more divergence, and increased self-efficacy. ACM Transactions on Computer-Human Interaction, 17(4), 18:1-18:24.

Dunne, D., \& Martin, R. (2006). Design thinking and how it will change management education: An interview and discussion. Academy of Management Learning \& Education, 5(4), 512-523.

Dweck, C. S. (2006). Mindset: The new psychology of success. New York: Random House.

Edelson, D. C. (2002). Design research: What we learn when we engage in design. Journal of the Learning Sciences, 11(1), 105-121. doi:10.1207/S15327809JLS1101_4

Gardner, S. K. (2008). "What's too much and what's too little?" The process of becoming an independent researcher in doctoral education. The Journal of Higher Education, 79(3), 326-350.

Gibbons, M., Limoges, C., Nowotny, H., Schwartzman, S., Scott, P., \& Trow, M. (1994). The new production of knowledge: The dynamics of science and research in contemporary societies. London: SAGE Publications, Ltd.

Glaser, B. G., \& Strauss, A. L. (1967). The discovery of grounded theory: Strategies for qualitative research. Chicago: Aldine Publishing Company.

Goleman, D. (2004). What makes a leader? Harvard Business Review, 82(1), 82-91. 
Ulibarri, Cravens, Cornelius, Royalty, \& Nabergoj

Goleman, D. (2005). Emotional intelligence. New York: Bantam Books.

Grossman-Kahn, B. (2011, December 27). Defining creative confidence. Children's Creativity Museum Education Blog. Retrieved from http://childrenscreativity.wordpress.com/2011/12/27/definingcreative-confidence/

Grover, V. (2007). Successfully navigating the stages of doctoral study. International Journal of Doctoral Studies, 2, 9-21. Retrieved from http://www.ijds.org/Volume2/IJDSv2p009-021Grover21.pdf

Hall, S. S. (1998, November 29). Lethal chemistry at Harvard. The New York Times. Retrieved December 27, 2013, from http://www.nytimes.com/1998/11/29/magazine/lethal-chemistry-atharvard.html?pagewanted=all

Halse, C., \& Mowbray, S. (2011). The impact of the doctorate. Studies in Higher Education, 36(5), 513525 .

Hassi, L., \& Laakso, M. (2011). Design thinking in the management discourse: Defining the elements of the concept. In 18th International Product Development Management Conference, IPDMC. Delft.

Hasso Plattner Institute of Design at Stanford. (2010). bootcamp bootleg. Retrieved from http://dschool.stanford.edu/wp-content/uploads/2011/03/BootcampBootleg2010v2SLIM.pdf

Haynes, C., \& Bulosan, M. (2012). My world is not my doctoral program...or is it? Female students' perceptions of well-being. International Journal of Doctoral Studies, 7, 1-17. Retrieved from http://ijds.org/Volume7/IJDSv7p001-017Haynes329.pdf

Heinze, T., Shapira, P., Rogers, J. D., \& Senker, J. M. (2009). Organizational and institutional influences on creativity in scientific research. Research Policy, 38(4), 610-623.

Hollingsworth, R. (2012). Factors associated with scientific creativity. Euresis, 2, 77-112.

Hyun, J. K., Quinn, B. C., Madon, T., \& Lustig, S. (2006). Graduate student mental health: Needs assessment and utilization of counseling services. Journal of College Student Development, 47(3), 247-266.

Jairam, D., \& Kahl, D. H. (2012). Navigating the doctoral experience: The role of social support in successful degree completion. International Journal of Doctoral Studies, 7, 311-329. Retrieved from http://ijds.org/Volume7/IJDSv7p311-329Jairam0369.pdf

Johansson, U., \& Woodilla, J. (2008). Towards a better paradigmatic partnership between design and management. Presented at the International DMI Education Conference, ESSEC Business School, Cery-Poin toise, France.

Jones, M. (2013). Issues in doctoral studies - forty years of journal discussion: Where have we been and where are we going? International Journal of Doctoral Studies, 8, 83-104. Retrieved from http://ijds.org/Volume8/IJDSv8p083-104JonesFT129.pdf

Kearns, H., Gardiner, M., \& Marshall, K. (2008). Innovation in PhD completion: The hardy shall succeed (and be happy!). Higher Education Research \& Development, 27(1), 77-89.

Kelley, T., \& Kelley, D. (2013). Creative confidence: Unleashing the creative potential within us all. New York: Drown Business.

Kolb, D. A. (1984). Experiential learning: Experience as the source of learning and development. Englewood Cliffs, NJ: Prentice-Hall.

Kolb, D. A., Boyatzis, R. E., \& Mainemelis, C. (2000). Experiential learning theory: Previous research and new directions. In R. J. Sternberg \& L.-F. Zhang (Eds.), Perspectives on cognitive, learning, and thinking styles (pp. 193-210). New Jersey: Lawrence Erlbaum.

Lindberg, T., Meinel, C., \& Wagner, R. (2011). Design thinking: A fruitful concept for IT development? In C. Meinel, L. Leifer, \& H. Plattner (Eds.), Design thinking (pp. 3-18). Berlin Heidelberg: Springer. Retrieved from http://link.springer.com/chapter/10.1007/978-3-642-13757-0_1

Lindberg, T., Noweski, C., \& Meinel, C. (2010). Evolving discourses on design thinking: How design cognition inspires meta-disciplinary creative collaboration. Technoetic Arts, 8(1), 31-37. 
Loehle, C. (1990). A guide to increased creativity in research: inspiration or perspiration? BioScience, $40(2), 123-129$.

Lovitts, B. E. (2005). Being a good course-taker is not enough: A theoretical perspective on the transition to independent research. Studies in Higher Education, 30(2), 137-154.

Lovitts, B. E. (2008). The transition to independent research: Who makes it, who doesn't, and why. The Journal of Higher Education, 79(3), 296-325.

Mayer, J. D., \& Salovey, P. (1993). The intelligence of emotional intelligence. Intelligence, 17, 433-442.

McDonagh, D., \& Thomas, J. (2010). Rethinking design thinking: Empathy supporting innovation. Australasian Medical Journal, 3(8), 458-464.

Mindfulness in the corporate world: How businesses are incorporating the eastern practice. (2012, August 29). Huffington Post. Retrieved March 14, 2014, from http://www.huffingtonpost.com/2012/08/29/mindfulness-businesses-corporate-employeesmeditation n $1840690 . \mathrm{html}$

Plattner, H., Meinel, C., \& Leifer, L. J. (2011). Design thinking: Understand - improve - apply. Heidelberg; New York: Springer.

Rauth, I., Köppen, E., Jobst, B., \& Meinel, C. (2010). Design thinking: An educational model towards creative confidence. In Proceedings of the 1st International Conference on Design Creativity ICDC 2010. Kobe, Japan. Retrieved from http://papers.designsociety.org/design_thinking_an_educational_model_towards_creative_confidence. paper.30267.htm

Runco, M. A., \& Albert, R. S. (2010). Creativity research: A historical view. In J. C. Kaufman \& R. J. Sternberg (Eds.), The Cambridge Handbook of Creativity (pp. 78-94). New York: Cambridge University Press.

Sawyer, R. K. (2006). Educating for innovation. Thinking Skills and Creativity, 1(1), 41-48.

Schön, D. A. (1983). The reflective practitioner: How professionals think in action. New York: Basic Books.

Schön, D. A. (1990). Educating the reflective practitioner. San Francisco: Jossey-Bass.

Seelig, T. L. (2012). InGenius: A crash course on creativity. New York: HarperOne.

Simonton, D. K. (2004). Creativity in science: Chance, logic, genius, and Zeitgeist. Cambridge, UK; New York: Cambridge University Press.

Spaulding, L. S., \& Rockinson-Szapkiw, A. J. (2012). Hearing their voices: Factors doctoral candidates attribute to their persistence. International Journal of Doctoral Studies, 7, 199-219. Retrieved from http://ijds.org/Volume7/IJDSv7p199-219Spaulding334.pdf

Stanford University. (2014, April 23). Graduate profile: Stanford University facts. Retrieved April 27, 2014, from http://facts.stanford.edu/academics/graduate-profile

Sternberg, R. J., \& Lubart, T. I. (1999). The concept of creativity: Prospects and paradigms. In R. J. Sternberg (Ed.), Handbook of creativity (pp. 3-15). New York: Cambridge University Press.

Sternberg, R. J., O’Hara, L. A., \& Lubart, T. I. (1997). Creativity as investment. California Management Review, 40(1), 8-21.

Tischler, L. (2009). Ideo's David Kelley on “design thinking." FastCompany.com, 5.

Voss, J. F., \& Post, T. A. (1988). On the solving of ill-structured problems. In M. T. H. Chi, R. Glaser, \& M. J. Farr (Eds.), The nature of expertise. Hillsdale, NJ: Lawrence Erlbaum Associates.

Wang, F., \& Hannafin, M. J. (2005). Design-based research and technology-enhanced learning environments. Educational Technology Research and Development, 53(4), 5-23. doi:10.1007/BF02504682

Watkins, C. (2010). Learning, performance and improvement. INSI Research Matters, 34. 
Weinert, F. E. (2000). Individuelle kreativität und kollektives ergebnis [Individual creativity and collective income]. Max-Planck-Inst. für Psycholog. Forschung.

Zupan, B., Svetina Nabergoj, A., Stritar, R., \& Drnovšek, M. (2013). Action-based learning for millennials: Using design thinking to improve entrepreneurship education. In E. Doyle, P. Buckley, \& C. Carroll (Eds.), Innovative business school teaching: Engaging the millennial generation (pp. 128-138). New York: Routledge.

\section{Biographies}

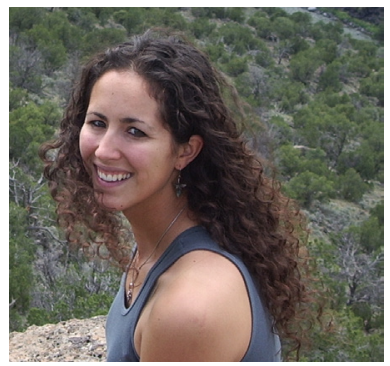

Nicola Ulibarri is a doctoral candidate in the Emmett Interdisciplinary Program in Environment and Resources at Stanford University. Her research uses political, social, and technical perspectives to evaluate the sustainability of environmental planning and decision-making practices, with a focus on collaborative governance and water resources management.

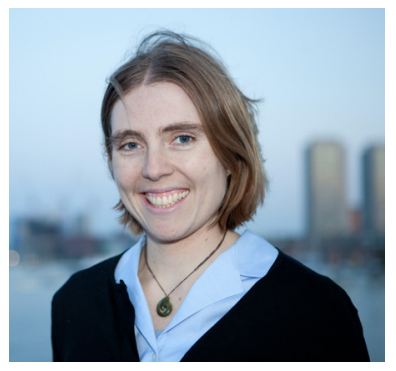

Amanda E. Cravens is a postdoctoral researcher at Stanford University. Trained as an interdisciplinary social scientist, she is broadly interested in how groups of people learn, negotiate, and make decisions together. Her current research is investigating how using information technology influences public policy decision making. As a teacher she has developed and evaluated experiential learning curricula for environmental policy, negotiation, and research design courses.

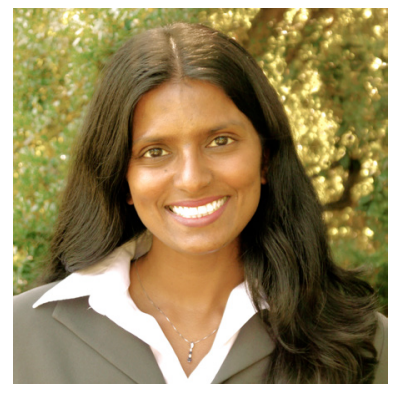

Marilyn Cornelius is Principal Consultant and Managing Director at d.cipher pathways, LLC. She holds a doctorate from the Emmett Interdisciplinary Program in Environment and Resources (E-IPER) at Stanford. Her research interests are in designing behavioral solutions to reduce greenhouse gas impacts related to energy use, food, and transportation in the residential sector, including designing, implementing, and evaluating a behavior change curriculum for high school.

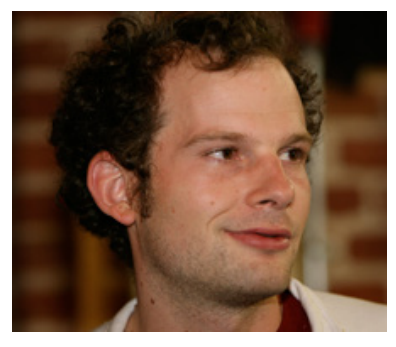

Adam Royalty is the Lead Design Research Investigator at the Hasso Plattner Institute of Design (d.school) at Stanford University. His research focuses on how to authentically measure the impact of human centered design. Since joining the d.school, Adam has taught multiple design thinking courses and has worked to deepen the creative capacity of organizations in a dozen countries. Prior to his role as a researcher, he led education projects in the d.school's K-12 Lab. Adam holds an MA in Learning, Design, and Technology from Stanford University. 


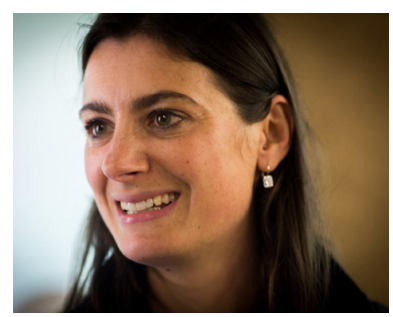

Anja Svetina Nabergoj is an Assistant Professor at the Faculty of Economics, University in Ljubljana in Slovenia, where she teaches undergraduate and graduate entrepreneurship courses. Her main focus is developing and using design thinking methodology and adapting it for entrepreneurship courses and business school curriculum. She is also a Lecturer at Stanford University's Hasso Plattner Institute of Design. In her work she focuses on helping individuals, teams and organizations build their creative confidence. Her recent research focuses on design thinking, primarily in the context of entrepreneurship education and doctoral studies. 